\title{
The early communicative skills among a sample of Egyptian infants and toddlers
}

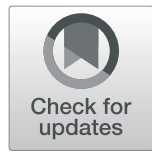

Hassnaa Othman Mohammed ${ }^{1 *}$ (D) and Nesreen Fathi Mahmoud ${ }^{2}$

\begin{abstract}
Background: The development of early communicative skills has always been an area of interest in the medical field. Although the assessment of early communicative skills and its relation to language development is important, it is a deficient field of research among Egyptian children. Therefore the current work is aiming to explore the early communicative skills among a sample of infants and toddlers in Egypt and to develop an Arabic assessment tool for early communicative abilities. A cross-sectional study was carried on in the period between January 2015 and January 2018. The study developed an assessment tool for assessment of early communicative skills (Early Communicative Skills Assessment Checklist in Arabic (ECSAC)) and then examined these communicative abilities among a sample of normally developed 151 Egyptian infants and toddler [83 (55\%) males and 68 (45\%) females] aged between 6 and 24 months. Then, the normative data of development of the early communicative skills were determined for the children in the period from 6 to 12 months, 13 to 18 months, and 19 to 24 months.

Results: ECSAC was a valid and reliable tool for assessment of early communicative skills among Egyptian children. The normal age of development of different early communicative skills was determined. Both sexes performed equally on the checklist.

Conclusion: ECSAC is a valid and reliable assessment tool among Egyptian infants and toddler.

Keywords: Early communicative skills, Predictors of language development, Pre-linguistic skills of language development, Social and gesture development
\end{abstract}

\section{Background}

The communicative system that leads language development among infants and toddlers is called prelinguistic communication. The body of research in this field suggested that the transition from prelinguistic to linguistic communication is a continuous process [1]. The nature of the relation between the two periods (i.e., prelinguistic and linguistics) raises the significance of early screening of specific skills in the period which is related to language development [2]. Research has identified a collection of skills in this period and called them language predictors [3]. They are called so because of their reliable predictability of later language development [4].

\footnotetext{
* Correspondence: drmelwardany@yahoo.com

${ }^{1}$ Department of the Medical Studies for Children, Faculty of Postgraduate Childhood Studies, Ain Shams University, Cairo, Egypt

Full list of author information is available at the end of the article
}

The following are some early communicative skills that could be identified as language predictors: shared positive affect [5], gaze shift, response to joint attention bids [6], initiation of joint attention [6], initiation of behavior regulation [5], gestures [7], language comprehension [8, 9], variation of consonant in syllables [5], words $[9,10]$ and word combination [5], imitation [6], and play [6]. Moreover, the sociality of the child with his/her parents and peers [11] and the role of the amount and mode of environmental stimulation should be included [12]. The current work explored the developmental profile of most of these early communicative skills among Egyptian toddler and infants.

The typical developmental profile regarding the development of these prelinguistic skills varies widely in literature. One of the most studied prelinguistic skills is 
joint attention [13], pointing [14], social interaction [15], symbolic play [6], and gesture use [14].

Joint attention is developed from three essential developmental contributors which include (a) sharing attention, (b) sharing affect, and (c) sharing intentions [4]. These skills emerged over the first year of life [6]. The infant showed an amazing ability to share attention at birth. This ability grows up, and a higher skill called joint attention was observed among infants' behavior by the end of the first year of life [16].

The second well-studied prelinguistic skill is pointing. Literature identified two types of pointing (proto-imperative and proto-declarative) [14]. Pointing emerges around $8-10$ months in typically developing children $[17,18]$. At 9-10 months of age, a child begins to use sounds, gestures, and other behaviors to communicate intentionally [8]. These early communicative skills contribute largely to the emergence of two language domains (receptive and expressive) [3].

The capacity to symbolize emerges in the period between first and second year of life [5]. This capacity develops from the child's ability to actively manipulate and explore properties of objects during the first year [6].

Immediate imitation usually develops by $6-9$ months. However, the deferred or delayed imitation emerges by 12-14 months [19].

The capacity to recognize the meaning of words outside familiar contexts is termed decontextualized comprehension. This capacity emerges between 12 and 18 months [7].

At 18-24 months, organizational shift occurs in the linguistic system [20]. The infants begin to discover that things have names at $\sim 12-13$ months of age [8]. Gao et al. [21] concluded that early assessment, followed with early intervention, of many communication disorders could be carried out using a comprehensive assessment tool of early communicative skills-especially the social one. This will further maximize the developmental outcome.

Additional file 1 shows the age of development of some early communicative skills.

Owing to marked variability among normative values of some early communicative skills in worldwide and Egypt, as shown in Additional file 1, the present study was addressed to determine language predictors in Egyptian infants and toddlers aiming toward early identification of communications problems.

\section{Objectives of the study}

The following were the objectives of the study:

1- Exploring the early communicative skills among a sample of infants and toddlers in Egypt.
2- Developing an Arabic assessment tool for early communicative abilities.

\section{Methods}

This study was a cross-sectional study that was carried out between January 2015 and January 2018. The participants were randomly recruited from nursery and pediatric clinics from Beni-Suef and Cairo. Two areas were randomly selected in Cairo (El-Zaytoon and Kobbry El-Qubba). In addition, children of some relative and colleagues were also included; the random selection of different areas covered different socioeconomic statuses within Egypt. Among these locations, families with a child between 6 and 24 months were invited to join the study. The parents or one of them was informed about the objectives of the study, and written consent was taken. The study received the approval of the ethical committee of one of the Egyptian universities.

Inclusion criteria include the following:

1- Children of both sexes between 6 and 24 months attending the pediatric clinic or in the nursery.

2- Children without any risk factor in their perinatal period.

3- Children with normal developmental milestones in areas like parent recognition, social smile, motoric development, self-care, and teething.

4- Absence of any past history of traumatic brain injury, convulsions, or ear disease.

5- Clinically, absence of any morphological abnormalities (e.g., specific facial characteristics of syndromic disorders).

6- There is no concern of the mother about her child communicative development (not seeking the medical advice for communicative problem).

7- Their parent speaking Arabic language (El-Qahera colloquial) as their native language.

Exclusion criteria include the following:

1- Any perinatal risks regarding communication disorders.

2- Presence of any morphological abnormalities or developmental delay in areas mentioned before (motoric, parent recognition, self-care, and teething).

3- Presence of past history of ear disease, traumatic brain injury, chronic illnesses, and any medication intake.

4- The use of foreign languages when communicating with the child.

\section{Procedure}

The assessment protocol included the following: 
1- A clinical interview with the parents or a single guardian. The clinical interview included personal history (name, age, sex, history of consanguinity, family history of developmental abnormalities); perinatal history (all risk factors of developmental disorders were asked about); developmental history (mother recognition, father recognition, setting, walking, toilet training, teething, self-care); nursery; past history of head trauma; ear, nose, and throat disease; chronic illnesses; drug intake; and convulsions.

2- Early Communicative Skills Assessment Checklist in Arabic (ECSAC): this checklist was designed by combining and modifying three major assessment tools. These assessment tools are designed to assess the pattern of development of early communicative skills. It explores the prelinguistic developmental milestones. These assessment tools included Communication and Symbolic Behavior Scales Developmental Profile (Infant/Toddler Checklist) (CSBS) [5], Portage [22], and modified preschool language scale (Arabic edition) [23].

ECSAC is a parent-report screening tool comprising of 23 questions designed to measure relevant early communicative milestones and language development in children aged 6 to 24 months. They included passive joint attention, active joint attention, use of gestures, expressive language, receptive language, object use, and social interaction. The last one included the social skills exhibited by the child with his/her parents and peers. The parent was asked to complete the checklist which takes only 5-10 min to be completed. When a written answer could not be obtained for any reason, verbal response was considered sufficient.

\section{Checklist component}

The checklist is composed of two sheets of papers. The first sheet is the items of the checklist, and the second contains the scoring system and clinician's recommendations.

\section{Scoring of Early Communicative Skills Assessment Checklist in Arabic}

The checklist is composed of 23 questions. The ratings are a three-point scale. Children in the current work were given a score indicating how often they showed the assessed domain in their daily life. Getting score 1 indicated that their child did not show this behavior during their observation; score 2 indicated that they sometimes show this behavior whereas 3 indicated that this behavior was always shown in the child's activity during their observation $(1=$ not yet, $2=$ sometimes, $3=$ often $)$. The sum of each scale is calculated and is compared with the normal values. Table 1 showed the scoring of ECSAC.

The number of points earned in each scale should be totaled to yield seven individual scale scores. The scores can be totaled on the right side of the box labeled for each scale on the checklist and then transferred to the checklist screening report form. The number of possible points is 69 .

\section{Reliability and validity evidences of Early Communicative Skills Assessment Checklist in Arabic Reliability of the checklist}

Reliability is defined as the consistency of measurements obtained by the instrument across the population [24].

a- Test-retest reliability: the correlation between the test-retest validated the checklist. It is considered as an efficient way of measuring the stability of an instrument. To examine the test-retest reliability, 40 individuals are given the same test twice. In each time, the test is repeated under conditions that are as similar as possible. The interval chosen between test and retest was 2 weeks. Reliability coefficients are presented in Table 2, and it is highly significant in all test items. This means that, there is a high significance of the correlation between test-retest scores.

The reliability co-efficiency is obtained by doing Pearson product correlation coefficients between test and retest scores. If $p$ value is less than 0.0001 at different test scales, this means that test retest is genuinely correlated.

b- Internal consistency reliability: analyses were made to make correlation between each item score and total score of the checklist as illustrated in Table 3 and $p$ value was $\leq 0.01$. This indicates highly significant positive correlation which in turn supports internal consistency validity of the ECSAC.

Table 1 The number of points in each scale

\begin{tabular}{ll}
\hline Scales & Total possible points \\
\hline Passive joint attention & 12 (4 to 12) \\
Active joint attention & $12(4$ to 12$)$ \\
Use of gestures & $12(4$ to 12$)$ \\
Expressive language & $9(3$ to 9$)$ \\
Language comprehension & $6(2$ to 6$)$ \\
Use of objects & $9(3$ to 9$)$ \\
Social interaction & $9(3$ to 9$)$
\end{tabular}

The table shows the minimum and the maximum number of points earned in each scale 
Table 2 The internal consistency reliability of ECSAC

\begin{tabular}{lll}
\hline Scales & Reliability co-efficiency & $p$ value \\
\hline Passive joint attention & $0.9^{*}$ & $<0.0001$ \\
Active positive attention & 0.8 & $<0.0001$ \\
Gesture use score & 0.7 & $<0.0001$ \\
Expressive language score & 0.7 & $<0.0001$ \\
Language comprehension score & $0.9^{*}$ & $<0.0001$ \\
Object use score & 0.7 & $<0.0001$ \\
Social interaction score & 0.7 & $<0.0001$
\end{tabular}

The table shows the reliability co-efficiency between the test and retest items. There is a significant correlation between test and retest score

"The highest significance was in the passive attention and language comprehension score

\section{Validity}

Validity is described as "what the test measures and how well it does so" [25]. ECSAC was validated using the following:

a- Content validity (judgments' validity): the preliminary content was determined by a comprehensive review of current theory and research literature. Moreover, two independent, experienced, and bilingual phoniatricians and one psychologist judged all items of the checklist for language and cultural appropriateness as being completely relevant to the purpose for which they were meant, and they agreed that the checklist was suitable to judge what they were constructed for. The seven scales of ECSAC are intended to cover a wide range of observable indicators related to general concept of early communicative skills.

See Additional file 2 for the definition and examples.

Table 3 The correlation between the scores of each item of the checklist and total

\begin{tabular}{ll}
\hline Dimensions & Cronbach's a \\
\hline Shared positive affect and shared attention & 0.808 \\
Initiation of joint attention & 0.815 \\
Gesture use score & 0.856 \\
Expressive language score & 0.816 \\
Language comprehension score & 0.765 \\
Object use score & 0.837 \\
Social interaction score & 0.863
\end{tabular}

The table shows the reliability co-efficiency between each scale score and the total scale score. The correlation is significant between all of the scale score and the total score. Such result is denoting inter-correlation between the checklist scales

Acceptable when $a \geq 0.7$ and $<0.8$

Good when $a \geq 0.8$ and $<0.9$

Excellent when $a \geq 0.9$ b- Construct validity (internal consistency): it is a measure of checklist homogeneity. Correlation of each scale subitems with total scale score was done. Statistically strong correlation values were found when $r=0.5-1$, while medium correlation values were found when $r=0.3-0.5$.

Correlation coefficients for internal consistency ranged between 0.765 and 0.863 (highly positive significant correlation), and this proves the strong internal consistency of the test and that the test is valid. Table 4 shows the correlation coefficient between each scale total score and its subitems.

Microsoft Excel 2013 was used for data entry, and the statistical package for social science (SPSS) version 21 [26] (SPSS, Armonk, New York: International Business Machines Corporation) was used for data analysis. Simple descriptive statistics (arithmetic mean and SD) were used for the summary of quantitative data, and frequencies were used for qualitative data. The bivariate relationship was displayed in cross-tabulations, and

Table 4 The internal consistency of the seven scales of ECSAC

\begin{tabular}{|c|c|c|}
\hline Dimension & Questions & $r$ \\
\hline \multirow[t]{4}{*}{ Passive joint attention } & Q1 & $0.838^{*}$ \\
\hline & Q2 & $0.816^{*}$ \\
\hline & Q3 & $0.776^{*}$ \\
\hline & Q4 & $0.749^{*}$ \\
\hline \multirow[t]{4}{*}{ Active joint attention } & Q5 & $0.791^{*}$ \\
\hline & Q6 & $0.852^{*}$ \\
\hline & Q7 & $0.769^{*}$ \\
\hline & Q8 & $0.838^{*}$ \\
\hline \multirow[t]{4}{*}{ Gesture use scale } & Q9 & $0.758^{*}$ \\
\hline & Q10 & $0.898^{*}$ \\
\hline & Q11 & $0.777^{*}$ \\
\hline & Q12 & $0.785^{*}$ \\
\hline \multirow[t]{3}{*}{ Expressive language scale } & Q13 & $0.754^{*}$ \\
\hline & Q14 & $0.781^{*}$ \\
\hline & Q15 & $0.764^{*}$ \\
\hline \multirow[t]{2}{*}{ Receptive language scale } & Q16 & $0.899^{*}$ \\
\hline & Q17 & $0.857^{*}$ \\
\hline \multirow[t]{3}{*}{ Object use scale } & Q18 & $0.788^{*}$ \\
\hline & Q19 & $0.827^{*}$ \\
\hline & Q20 & $0.880^{*}$ \\
\hline \multirow[t]{3}{*}{ Social interaction scale } & Q21 & $0.759^{*}$ \\
\hline & Q22 & $0.765^{*}$ \\
\hline & Q23 & $0.787^{*}$ \\
\hline
\end{tabular}

The table shows the correlation co-efficiency between each scale subitems and the total scale score. Results denoting that there is a strong correlation between each scale total score and its subitem score

$r$ Pearson correlation, $r^{*}$ is an indication of strong correlation 
comparison of proportions was performed using the chisquare and Fisher's exact tests where appropriate. $T$ independent, one-way ANOVA and post hoc tests were used to compare normally distributed quantitative data. The level of significance was set at probability $(p)$ value $<0.05$.

\section{Results}

\section{Descriptive statistics}

The current work was conducted on 151 Egyptian children; their ages ranged between 6 and 24 months [ 83 (55\%) males and 68 (45\%) females]. The mean age of the whole studied sample was $15 \pm 6$ months. The studied sample was classified according to the age into three groups: group a, group b, and group c. Group a included $56(37 \%)$ children aged from 6 to 12 months, group b included 40 (26\%) children aged from 13 to 18 months, whereas group (c) included 55 (36\%) children aged $>18$ months. Table 5 demonstrates the demographic data of the whole studied sample.

Table 6 describes the mean value of the responses obtained in the seven assessed scales of the checklist among the whole studied sample.

Table 7 determines the mean scores earned by the children in each early communicative scale among the three studied group (group a, group b, and group c). Such finding indicates that there is a skillful mastering of different early communicative scale among studied sample.

\section{Comparative statistics}

Table 8 uses Tukey HSD (sub test of analysis of variance) to compare the mean score of each scale with the other one in the three groups. There was a significant difference between the mean score gained in each scale among the three studied sample.

Table 9 used the Pearson correlations to correlate between scoring in language domains (receptive and expressive) on one hand and the scoring in different checklist scales on the other hand. It was found that there is a moderate direct proportional correlation between receptive language score and passive joint attention, active joint attention, symbolic and gesture use score, object use score, and social interaction score. Moderate direct proportional correlation were also found between expressive language score and passive joint attention, active joint attention, gesture use score, object use, and social scale score.

Table 10 compares the mean score obtained by male and female participants in different scales. Results showed that statistical difference was not significant and $p$ value was more than 0.05 .

\section{Discussion}

In the past 10 years, there is an increased awareness of the first 2 years of human life in various aspects: physical, cognitive, social, and emotional. One area of great influence on a child's cognitive, social, emotional, and academic well-being is language development. Estimation of prevalence of language disorders showed great variability. It ranged from 2 to 19\% [27]. Gad-Allah et al. [28] estimated the prevalence of communication disorders among a sample of 852 children. Their ages ranged between 3 and less than 6 years. They found that language disorders were found in $30 \%$ of their sample. They recommended that special attention should be directed to this population in order to address early identification and intervention.

These facts raised the need for prognostic values that have the ability to predict language development especially if they were repeatedly assessed overtime.

Early communicative assessment among children aged 6-24 months was widely discussed in literature. Each work composed their own tool with certain skills and termed them as prelinguistic skills. The prelinguistic skills are group of non-verbal means of communication. They included gestures, vocalization, eye gaze, and expressive abilities [27]. It was discussed by Bates and his

Table 5 Demographic data of the whole studied sample

\begin{tabular}{|c|c|c|c|c|c|c|c|c|c|c|}
\hline \multirow{2}{*}{$\begin{array}{l}\text { The whole } \\
\text { studied } \\
\text { sample }\end{array}$} & \multirow[t]{2}{*}{ Mean age $( \pm S D)$} & \multicolumn{2}{|c|}{ Sex distribution } & \multirow{2}{*}{$\begin{array}{l}\text { Mean } \\
\text { ages } \\
( \pm \text { SD })\end{array}$} & \multirow{2}{*}{$\begin{array}{l}\text { Sub- } \\
\text { groups }\end{array}$} & \multirow[t]{2}{*}{ No. (\%) } & \multicolumn{3}{|c|}{ Sex distribution } & \multirow{2}{*}{$\begin{array}{l}\text { Mean } \\
\text { ages } \\
\text { in } \\
\text { month }\end{array}$} \\
\hline & & Type & No. (\%) & & & & Type & No. (\%) & Mean age & \\
\hline \multirow[t]{6}{*}{151 children } & 15.68 months $( \pm 7.24)$ & M & 83 (55\%) & 15.63 & a & $56(37 \%)$ & M & 33 & 8.18 & \multirow[t]{2}{*}{8.44} \\
\hline & & & & & & & $\mathrm{F}$ & 23 & 8.91 & \\
\hline & & $\mathrm{F}$ & $68(45 \%)$ & 15.73 & $b$ & $40(26 \%)$ & M & 25 & 16.44 & \multirow[t]{2}{*}{16.16} \\
\hline & & & & & & & $\mathrm{F}$ & 15 & 15.85 & \\
\hline & & & & & c & $55(36 \%)$ & M & 15 & 22.29 & \multirow[t]{2}{*}{22.37} \\
\hline & & & & & & & $\mathrm{F}$ & 30 & 22.45 & \\
\hline Total & 151 & & & & & & 151 & & & \\
\hline
\end{tabular}

Table describes some socio-demographic data (number of participants from both sex as well as their mean ages) of the whole studied sample as well as its groups (groups a, b, c) 
Table 6 The mean response of the whole studied sample in different prelinguistic skills

\begin{tabular}{|c|c|c|c|c|c|}
\hline Prelinguistic skills & Minimum & Maximum & Mean score $( \pm$ SD) & 25th percentile & 75th percentile \\
\hline Passive joint attention & 6 & 12 & $10.4( \pm 1.61)$ & 10 & 12 \\
\hline Active joint attention & 4 & 12 & $9.15( \pm 1.64)$ & 8 & 11 \\
\hline Gesture use & 4 & 12 & $8.62( \pm 1.28)$ & 6 & 11 \\
\hline Expressive language & 3 & 9 & $5.55( \pm 1.01)$ & 5.1 & 6.99 \\
\hline Language comprehension & 2 & 6 & $4.62( \pm 0.763)$ & 4 & 5 \\
\hline Object use & 3 & 9 & $6.55( \pm 1.19)$ & 4.92 & 8.01 \\
\hline Social interaction & 3.99 & 9 & $7.41( \pm 1.14)$ & 6.99 & 9 \\
\hline
\end{tabular}

The table shows the minimum, maximum, the mean score, and the 25 th and 75 th percentile earned by participants in the seven assessed scales

colleagues [29] as series of gesturing (giving, pointing, showing, and ritualized reaches). Early sociocognitive skills was reported by Bates [8] as speech sound perception and production, object recognition and categorization, imitation, joint reference, and intentionality act. Määttä [27] collected a larger number of prelinguistic skills. They included social engagement [30], gaze following [31] and other forms of joint attention [32, 33], gestures [34], deferred imitation [35], symbolic play [36], early vocalizations [37], auditory language skills [38], language comprehension [39], and vocabulary size $[40,41]$.

These skills developed prior to linguistic mean of communication, and they are interrelated and subserve language development [27]. Bates et al. [9] reported that by the end of the first year, most children are able to coordinate attention between people and objects, engage in social exchanges, and communicate intentionally or using gestures and sounds that have shared meanings. Bates [8] showed that these skills are characterized by having a continuum with language development, and sometimes, it went parallel to language development (due to common underlying cognitive development) [42]. These factors are considered as building blocks for later language development [43]. However, Bates et al. [8] and Rescorla [44-47] illustrated that these skills are intermingled with each other and convey later on with language development (by its two domains). Bates et al. [8] described it as an early interactive process between early cognitive process and later language development. More specifically, Darrah et al. [48] described the development of these early cognitive skills by being nonlinear development. More specifically, many children showed deviations from their national standard.

The current work developed an assessment checklist of most of prelinguistic skills like joint attention, gestures, social interaction, gesture use, play, and language expressive abilities and receptive one. Firstly, the validity of the present checklist was proved by high significance of content validity as well as construct validity. The reliability of the current work was proved by high significant test-retest reliability and significant Cronbach's $\alpha$. The checklist can provide an adequate descriptive profile regarding certain early communicative skills among Egyptian infants and toddlers in the period between 6 and 24 months. Second, according to the data obtained by the application of the checklist on a sample of typically developed infants and toddlers, a normal

Table 7 The mean values scored by children in each domain in the three subgroups

\begin{tabular}{|c|c|c|c|c|c|}
\hline \multirow[t]{2}{*}{ Comm. domain } & & \multicolumn{4}{|l|}{ Age } \\
\hline & & Group a (age 6-12 months) & Group b (age 13-18 months) & Age 19-24 months & Total \\
\hline No & $M( \pm S D)$ & $42.68( \pm 4.30)$ & $55.10( \pm 6.5)$ & $59.67( \pm 3.20)$ & $52.29( \pm 7.37)$ \\
\hline Mean age & $M( \pm S D)$ & $6.53( \pm 0.95)$ & $7.55( \pm 1.17)$ & $8.22( \pm 1.03)$ & $7.41( \pm 1.14)$ \\
\hline Passive joint attention & $M( \pm S D)$ & $5.20( \pm 1.2)$ & $6.98( \pm 1.14)$ & $7.58( \pm 1.24)$ & $6.55( \pm 1.19)$ \\
\hline Active joint attention & $M( \pm S D)$ & $3.98( \pm 0.99)$ & $4.7( \pm 0.68)$ & $5.2( \pm 0.62)$ & $4.62( \pm 0.763)$ \\
\hline Gesture use & $M( \pm S D)$ & $4.45( \pm 0.93)$ & $5.48( \pm 0.90)$ & $6.75( \pm 1.19)$ & $5.55( \pm 1.01)$ \\
\hline Expressive language & $M( \pm S D)$ & $6.23( \pm 1.87)$ & $9.25( \pm 1.37)$ & $10.36( \pm 1.6)$ & $8.62( \pm 1.28)$ \\
\hline Receptive language & $M( \pm S D)$ & $7.11( \pm 2.04)$ & $9.93( \pm 1.44)$ & $10.4( \pm 1.36)$ & $9.15( \pm 1.64)$ \\
\hline Object use & $M( \pm S D)$ & $9.2( \pm 1.92)$ & $10.8( \pm 0.88)$ & $11.2( \pm 0.83)$ & $10.4( \pm 1.16)$ \\
\hline Social interaction & & 8.44 & 16.16 & 22.37 & $15.68( \pm 7.24)$ \\
\hline Full scale & & 56 & 40 & 55 & 151 \\
\hline
\end{tabular}

The table shows the mean score earned by the participants in each of the seven scales score as well as the total score in each study group $(a, b, c)$ 
Table 8 The significance of difference between the mean score in each scale among the three groups

\begin{tabular}{|c|c|c|c|c|}
\hline \multirow[t]{2}{*}{ Comm. domain } & & \multicolumn{3}{|l|}{ Age } \\
\hline & & Age 6-12 months & Age $13-18$ months & Age 19-24 months \\
\hline \multirow[t]{3}{*}{ Passive joint attention } & 19-24 months & $0.000^{*}$ & $0.000^{*}$ & - ------ \\
\hline & 13-18 months & $0.000^{*}$ & ------- & $0.000^{*}$ \\
\hline & 6-12 months & ------- & $0.000^{*}$ & $0.000^{*}$ \\
\hline \multirow[t]{3}{*}{ Active joint attention } & 19-24 months & $0.000^{*}$ & $0.007^{*}$ & ------- \\
\hline & 13-18 months & $0.000^{*}$ & -------- & $0.007^{*}$ \\
\hline & 6-12 months & ------- & $0.000^{*}$ & $0.000^{*}$ \\
\hline \multirow[t]{3}{*}{ Gesture use } & 19-24 months & $0.000^{*}$ & $0.044^{*}$ & -------- \\
\hline & 13-18 months & $0.000^{*}$ & -------- & $0.044^{*}$ \\
\hline & 6-12 months & ------ & $0.000^{*}$ & $0.000^{*}$ \\
\hline \multirow[t]{3}{*}{ Expressive language } & 19-24 months & $0.000^{*}$ & $0.009^{*}$ & ---- \\
\hline & 13-18 months & $0.000^{*}$ & ------ & $0.009^{*}$ \\
\hline & 6-12 months & ------- & $0.000^{*}$ & $0.000^{*}$ \\
\hline \multirow[t]{3}{*}{ Receptive language } & 19-24 months & $0.000^{*}$ & $0.000^{*}$ & -------- \\
\hline & 13-18 months & $0.000^{*}$ & ------ & $0.000^{*}$ \\
\hline & 6-12 months & ------ & $0.000^{*}$ & $0.000^{*}$ \\
\hline \multirow[t]{3}{*}{ Object use } & 19-24 months & $0.000^{*}$ & $0.004^{*}$ & ------ \\
\hline & 13-18 months & $0.000^{*}$ & ----- & $0.004^{*}$ \\
\hline & 6-12 months & --1-1-- & $0.000^{*}$ & $0.000^{*}$ \\
\hline \multirow[t]{3}{*}{ Social interaction } & 19-24 months & $0.000^{*}$ & 0.372 & -------- \\
\hline & 13-18 months & $0.000^{*}$ & ------- & 0.372 \\
\hline & $6-12$ months & -------- & $0.000^{*}$ & $0.000^{*}$ \\
\hline \multirow[t]{3}{*}{ The full scale } & 19-24 months & $0.000^{*}$ & 0.271 & ------- \\
\hline & 13-18 months & $0.000^{*}$ & ------- & 0.271 \\
\hline & 6-12 months & ------ & $0.000^{*}$ & $0.000^{*}$ \\
\hline
\end{tabular}

The table shows the $p$ value of the statistical difference between mean scores (in each scale) earned by the participants in the three studied group. The table shows that there was a significant statistical differences between the mean score of each scale when comparing the three studied groups $0.000^{*}=$ highly significant value

Table 9 The correlation between the scoring in expressive language scale and expressive language scale in one hand and scoring in each of the seven scales

\begin{tabular}{lllllll}
\hline Comm. domain & \multicolumn{2}{l}{ Expressive } & & \multicolumn{2}{l}{ Receptive } \\
\cline { 2 - 3 } \cline { 6 - 7 } Pearson correlation & $r$ & & $p$ value & & $r$ & $p$ value \\
\hline Passive joint attention & 0.533 & 0.000 & & 0.5 & 0.000 \\
Active joint attention & 0.624 & 0.000 & & 0.679 & 0.000 \\
Gesture use & 0.642 & 0.000 & & 0608 & 0.000 \\
Object use & 0.612 & 0.000 & & 0.607 & 0.000 \\
Social interaction & 0.577 & 0.000 & & 0.559 & 0.000 \\
\hline
\end{tabular}

The table shows that there is a moderate correlation between language scales (receptive and expressive scales) and the remaining scales

$r$ is the Pearson correlation; $<0.5$ weak correlation; between 0.5 and 0.7 moderate correlation; $>0.7$ strong correlation
Table 10 The mean scores of both sexes in different prelinguistic scales

\begin{tabular}{llll}
\hline Comm. domain & \multicolumn{3}{l}{ Age } \\
\cline { 2 - 4 } & Boys & Girls & $p$ value \\
\hline No & $51.56( \pm 4.36)$ & $53.26( \pm 0.37)$ & 0.254 \\
Mean age & $7.29( \pm 1.23)$ & $7.53( \pm 1.26)$ & 0.215 \\
Passive joint attention & $6.42( \pm 0.153)$ & $6.66( \pm 1.68)$ & 0.215 \\
Active joint attention & $4.5( \pm 0.94)$ & $4.72( \pm 0.96)$ & 0.225 \\
Gesture use & $5.37( \pm 1.29)$ & $5.73( \pm 1.53)$ & 0.136 \\
Expressive language & $8.74( \pm 1.44)$ & $8.6( \pm 2.36)$ & 0.765 \\
Receptive language & $8.84( \pm 2.28)$ & $9.62( \pm 2.04)$ & 0.201 \\
Object use & $10.4( \pm 0.96)$ & $10.4( \pm 0.96)$ & 0.435 \\
Social interaction & 15.63 & 15.73 & 0.322 \\
Full scale & 83 & 68 & 151 \\
\hline
\end{tabular}

The table determines the mean score earned by the participants of both sex in the seven scales of the checklist 
developmental profile was drawn. Therefore, the current checklist could be considered as an effective assessment tool of early communicative abilities among infants in Egypt.

The checklist provided a comprehensive understanding of social and cognitive behaviors that emerge during infancy in typically developing children. It highlighted the direction of correlation between development in different prelinguistic skills and receptive and expressive abilities among Egyptian infants. Charman et al. [49] reported that early assessment of communicative abilities could help in making decision regarding differential diagnosis of delayed language development. Moreover, Baron-Cohen et al. [50] clarified its significance in drawing the content and design of early intervention program.

The current checklist provides an adequate answer to parental concern regarding their infant's communicative abilities (during infancy) in the pediatric clinics. It examined that the many sociocognitive behaviors proved to have significant relation with language development among Egyptian infants in the period between 6 and 24 months.

This topic was widely discussed in literature. Many researchers examined certain criteria at a specific time (e.g., joint attention, gesture, imitation, and symbolization). However, fewer numbers developed an assessment tool that determines the development of different behaviors at different times $[5,51]$.

The present study examined the early communicative skills of 151 typically developed children by ECSAC. The studied sample was divided into three groups according to their age: group a included children aged 6-12 months, group b included children aged 13-18 months, and group c included children aged 19-24 months.

Administration of ECSAC revealed that the first group showed development of passive attention (i.e., shared affect as well as shared attention), while the second group showed increased mastering of shared affect, shared attention, and they start to respond to joint attention. Nearly complete mastering of the joint attention occurs in the third group. Butterworth [16] concluded that by the end of the first year of life, the child follows the caregiver's attentional focus in a process known as responding to joint attention. Shared attention typically begins at birth and continues to develop over the first year of life [6].

The second behavior which was examined in the current work is active joint attention or what is called initiation of behavior regulation. This behavior starts to develop among the current sample in the first group. The second group showed more mastering of this skill. The last group showed the highest score obtained by the current sample. Henderson et al. [52] and Wetherby et al. [53] differentiated between two types of pointing. They included pointing for initiating behavior regulation
(IBR) and pointing for initiating joint attention (IJA). IBR is requesting or protesting the presence of an object or action. IJA is sharing positive affect or interest in a referent or event. Carpenter et al. [13] and Seibert et al. [54] demonstrated that children between 6 and 18 months show systematic, age-related gains in IJA and IBR but with considerable individual differences. Mundy and Gomes [55] and Mundy et al. [56] reported that IBR and IJA are completely distinguishable from each other. Ulvund and Smith [57] claimed that IJA tends to be more frequently related to later language than does IBR. Moreover, only IJA distinguishes groups of children with autism from children with other disabilities who are matched on a variety of developmental measures [50, 58]. Other authors viewed pointing as fine motor act and should be preceded by suitable amount of cognitive development [14].

The slowing and decline in development of initiation of communicative bids, response to others joint attention bids, and play are usually reported as the first concern reported by parents of children, who later on received the diagnosis of Autism Spectrum Disorders (ASD) $[59,60]$.

Bates [8] reported that gesture developed as a presymbolization early communicative behavior. It included reaching, grasping, and turning the head away, waving, showing, and pointing. Early communicative act (gesturing and sound) is considered as the foundation for the emergence of first words and the transition to symbolic communication. The current work demonstrated that Egyptian children developed during the first year a rich gesture inventory. This was in agreement with what has been published by Charman and Stone [6]. In the current work, the first half of the second year showed an increase in accuracy and frequency of use of gesture. These findings are in line with what has been reported by $\mathrm{Wu}$ and Louis [61]. They reported that around the age of 12 months, the infants produce skillful combined communicative act to engage a social partner. They claimed that this prelinguistic communicative act play a crucial role in infant's transition from prelinguistic communication to linguistic communication [29]. Moreover, Paavola et al. [62] showed that 10-month-old infants' intentional communicative acts predict their comprehension and production scores measured by the MacArthur Communicative Development Inventory at 12 months.

Goldin and Meadow [63] and Iverson et al. [64] have shown in their work that gesture and vocal combination precede gesture and word combination. Furthermore, gesture-word combination precedes two-word combinations (and both were related to linguistic measures at 15 months) [65].

The current work demonstrated the development of expressive language skills. The results showed that 
during the second half of the first year, Egyptian infants produce syllables in their expressive inventory. During the first half of the second year of life, the expressive abilities increase, and single word is presented in the expressive inventory. During the second half of second year, the number of words increases markedly. Fenson et al. [66] gave a model about the expressive language development. They claimed that expressive skills move through developmental stages to reach single-word production around the end of the first year. By 18 months, infants typically produce around 50 words.

The receptive language was also explored in the current checklist. The assessed comprehensive abilities were ranging from respond to his name and number of simple orders the child can understand. Results showed that these skills start to develop by the end of the first year, and the second year achieved marked development.

Wetherby et al. [7] studied language comprehension in their work. They claimed that comprehension involves understanding of nonverbal and verbal communicative signals used by others. In their work, they concluded that by 9-12 months of age, children demonstrate nonverbal comprehension by responding to nonverbal cues such as gestural cues, situational cues, and intonation cues. By responding to this rich array of cues, a child may give a skillful language comprehension but yet not understand actual spoken words. Comprehension becomes decontextualized between 12 and 18 months as children recognize the meaning of words outside familiar contexts $[8,9]$.

Object use was also studied in the current work. Activities like number of toys and the abilities to demonsterate pretended play were included in this domain. Results showed that these activities started as early as the second part of the first year and increase gradually during the first and second half of the second year. Bates [8] provided a detailed description of development of this skill. They claimed that the child ability to actively explore objects and to imitate people leads to the ability to use familiar objects functionally and conventionally. This skill provides a backbone for development of pretend play. McLean and Snyder-McLean [67] concluded from their work that by age of 12 months, children are able to use a variety of familiar objects conventionally.

The capacity to acquire conventional use of objects is triggered by children's use of active learning strategies that involve exploring objects, observing others, listening to others, and learning from others [27].

Barnat et al. [19] determined that there are two types of imitation. The first developed at 6-9 months of age and called immediate imitation. The second type is termed deferred or delayed imitation. This type appeared in the child's inventory by the age of 12-14 months.

The last but not the least domain which was investigated in the current checklist is social interaction.
During assessment of this domain, the child's ability to understand peekaboo game and to interact with their peer was evaluated. Results showed that children showed early acquisition of this skill. They get a high score during the first year of life. During the second year of life children demonstrated more mastering of this skill. Bushnell [68] and Johnson et al. [15] reported in their work that the earliest manifestation of responsiveness to social interaction is the intense interest infants show in faces from a few hours after birth. Walden and Baxter [69], Walden and Ogan [70], Hertenstein and Campos [71], and Hornik et al. [72] all reported that infants use maternal emotional responses to guide their behavior in ambiguous situations by the latter part of the first year particularly for negative responses.

McCathren et al. [73] pointed out to the importance of normal social development among typically developed children. They reported that by the first birthday autism and typically developed children were distinguished by social communication and play features which included joint attention, social interaction, social anticipation, eye contact, complex babbling, gesture, word production, and response to his name. Social communication abnormalities are inborn deficits of autism children, which are primarily concerned and easy detectable at early ages (at or before the age of 18 months) by parents. They could be used together with play as the early signs to more accurate screening of such disease [74].

Reilly et al. [75] postulated that play has been called "the work of children" because play enable children to learn how to interact in their environment, discover their interests, and acquire cognitive, motor, speech, language, and social-emotional skills. The developmental stages of play in infants were discussed in a work by Pepper and Weitzman [73]. They determined that during infancy play begins with sensory-motor experiences, pass by cause/effect relationships, and ends by infant's ability to engage in nonverbal communication with their play partners. This emergence of reciprocal interactions is a foundation for later social skill development $[73,76]$.

Dawson et al. [77] illustrated a developmental trajectory of play. They reported that between the ages of 6 and 12 months, infants mainly explore the sensory characteristics of objects and develop more precise forms of object manipulation [9]. In the last quarter of the first year of life, the ability to relate two or more objects with each other emerges [13]. Examples of this type of play are called relational or combinational play. Functional play appears when a child is about 14 months old. At that age, the child can use (miniature) objects in the way they were intended (such as pushing a toy car). Three to 6 months later, the child is capable of symbolic play.

It is significant to mention that number of toys in the child environment has its significant impact on child 
mental development. Duech et al. [78] raised the notion that fewer toys in the child environment will help the child to engage in longer period of play with single toy which in turn develops creative play.

Playing is widely varied in children with ASD and differed completely from typically developed infants. However, the most extensively documented impairments are found in symbolic play [78, 79]. An early lack of symbolic play (combined with a deficit in joint attention) is highly predictive for a later diagnosis of ASD [78]. Symbolic play has also been found to discriminate between children with ASD and children with attention-deficit hyperactivity disorder in the second year of life [5].

In the current study, during parents meeting, the researchers noticed that period and type of play was markedly reduced especially the free play. Such finding might be attributed to the change of lifestyle which affects Egyptian culture.

When the checklist is inspected as a one unit, it was clear that the development in the prelinguistic period is characterized by synchronization in the development between different skills. Behaviors like joint attention, use of gesture, and imitation were developed in parallel manner. The same view was supported by Tomasello $[80,81]$. The second characteristic of the development in this period is the stability. It was shown in the results that Egyptian children scored higher in different scales when they got older. The same characteristic was supported by Reilly et al. [82] and Watt et al. [83].

The current work tried to find out the direction of growth in different domains in relation to language development (in receptive and expressive aspects). Data showed that there is moderate direct proportional correlation between the development among the remaining scales and the receptive aspect. The correlation between the same prelinguistic scales and the expressive score was also a moderate direct proportional one. The moderate correlation could be explained by the presence of more specific developmental factors which is required for the development of the expressive aspect of the language such as speech motor control or phonological development $[84,85]$. In addition to the age range of the studied sample. The majority of the examined children were in the period between 6 and 18 months, and this period is characterized by limited expressive abilities.

Rescorla [46, 47] did not support these correlations. The author postulated that there is a general association rather than specific association between specific factors and language development (what is called dimensional view of language). Laakso et al. [33], Watt et al. [83], and Wetherby and Prizant [5] interpreted the reason for the absence of reliable specific association by presence of strong interrelation between the early communicative skills which makes it difficult to make a selective association. They recommended that in order to find specific relation, the sample size should be much larger, the applied instrument should be more sensitive, and frequent follow-up should be used. The authors added that a broadband parental screener is only able to detect common trends in development. This is supported by the findings of Brooks and Meltzoff [31], Laakso et al. [33], and Watt et al. [83], who were able to find specific predictive relations using observational methods.

The current work studied the sex difference among ECSAC. The data showed that there was no statistically significant difference between male and female. This was similar to what has been studied by Määttä et al. [86]. They examined the role of gender difference in their infants and toddler behavioral and symbolic checklist. They clarified that although researchers have stated that boys outnumber the girls in the group of children with language difficulties, this is not the role in the prelinguistic skills assessment. However, Heilmann et al. [87] and Law et al. [74] reported the findings that there were sex differences in prelinguistic skills among their studied sample. Wetherby and Prizant [5] did not find any substantial sex differences in the standardization sample of the Infants and Toddler Checklist. Moreover, the results concerning the sex differences in the persistence of language problems are conflicting $[88,89]$. More research is needed to establish to what extent gender is a risk factor in the different subgroups of the population [74].

\section{Limitation of the study}

There was no limitation in the study.

\section{Conclusion}

The current work concluded that ECSAC is a valid and reliable assessment tool for early communicative skills among Egyptian infants and toddlers. The current work raised the notion of importance of early detection and early intervention of communicative disorders. This could be attributed by routine check of early communicative abilities among infants and toddlers in the primary care unit (using the current checklist). The present work recommended a longitudinal study which utilizes a larger sample of participants. This could help in better understanding of the nature of relationship between language development and early nonverbal communicative development.

\section{Supplementary information}

Supplementary information accompanies this paper at https://doi.org/10. 1186/s43163-020-00023-3.

Additional file 1. The normative values of some early communicative skills (both worldwide and in Egypt)

Additional file 2. Shows the definition of the items reported in the checklist 


\section{Abbreviations}

ECSAC: Early Communicative Skills Assessment Checklist in Arabic; CSBS: Communication and Symbolic Behavior Scales Developmental Profile (Infant/Toddler Checklist; SPSS: The statistical package for social science; IBR: Initiating behavior regulation; IJA: Initiating joint attention; ASD: Autism spectrum disorder

\section{Acknowledgements}

Thanks are due to the children and their parents who participated in this work for their compliance and patience.

\section{Authors' contributions}

HOM has a substantial contribution to the intellectual content, conception and design of this work. She participated in literature review and made the clinical study. She collected data and contribute to data analysis and interpretation. She wrote the manuscript. She agreed to be the corresponding author and the guarantor of this work. NFM has a substantial contribution to the study design and the intellectual contents. She participated in the study design and made the clinical study. She collected data and participate in its interpretation and she revised the manuscript and made a valuable editing. All authors have read and accepted the manuscript.

\section{Funding}

There is no funding resource.

\section{Availability of data and materials}

The datasets used and/or analyzed during the current study are available from the corresponding author on reasonable request.

\section{Competing interest}

There is no conflict of interest.

\section{Ethics approval and consent to participate}

The current work was conducted in accordance to the guidelines of ethical committee of Faculty of Medicine Beni-Suef University after receiving the committee's approval. Approval No: .FMBSUREC/03112019/Mahmoud. The parents of the participating children or one of them was informed about the objectives of the study, and written consent was taken.

\section{Consent for publication}

Not applicable.

\section{Author details}

'Department of the Medical Studies for Children, Faculty of Postgraduate Childhood Studies, Ain Shams University, Cairo, Egypt. ²Department of ENT, Faculty of Medicine, Beni-Suef University, Beni-Suef, Egypt.

\section{Received: 25 March 2020 Accepted: 13 July 2020}

Published online: 07 October 2020

\section{References}

1. Reddy V (1999) Prelinguistic communication. In: Barrett MD (ed) The development of language. Psychology Press, East Sussex, UK, pp 25-50

2. McCathren RB, Warren SF, Yoder PJ (1996) Prelinguistic predictors of later language development. In: Cole KN, Dale PS, Thal DJ (eds) Assessment of communication and language. Brookes, Baltimore, MD, pp 57-75

3. Wetherby A, Prizant B (1993) Communication and symbolic behavior scalesNormed Edition. Chicago, IL, Applied Symbolix

4. Stern D (1985) The interpersonal world of the infant. Basic Books, New York

5. Wetherby AM, Prizant BM (2002) Communication and symbolic behavior scales: developmental profile (1st normed ed.). Baltimore, MD, Brookes

6. Charman T, Stone W. Social and communication development in autism spectrum disorders: early identification, diagnosis, and intervention. In Tony C, Wendy S (eds.). Guilford Publications; 2006. 72 Spring Street, New York, NY Chapter (7) \&chapter (8).

7. Wetherby A, Reichle J, Pierce P (1998) The transition to symbolic communication. In: Wetherby A, Warren S, Reichle J (eds) Transitions in prelinguistic communication. Brookes, Baltimore, pp 197-230

8. Bates $E$ (1979) The emergence of symbols: cognition and communication in infancy. Academic Press, New York
9. Bates E, O'Connell B, Shore C (1987) Language and communication in infancy. In: Osofsky J (ed) Handbook of infant development. Wiley, New York, pp 149-203

10. Wetherby AM, Prizant BM (2001) In: Charman T, Stone W (eds) Social and communication development in autism spectrum disorders: early identification, diagnosis, and intervention. Guilford Publications: Paul H. Brookes Publishing Co, New York

11. Landa RJ, Holman KC, Garrett-Mayer E (2007) Social and communication development in toddlers with early and later diagnosis of autism spectrum disorders. Archives of General Psychiatry. 64:853-864

12. Justice LM, Jiang H, Strasser K (2017) Linguistic environment of preschool classrooms: what dimensions support children's language growth? Early Childhood Research Quarterly 42:79-92

13. Carpenter M, Nagell K, Tomasello M (1998) Social cognition, joint attention, and communicative competence from 9 to 15 months of age. Monographs of the Society for Research in Child Development. 63(4):255

14. Iverson JM, Goldin-Meadow S (2005) Research report gesture paves the way for language development. Psychological Science 16(5)

15. Johnson MH, Dziurawiec S, Ellis H, Morton J (1991) Newborns' preferential tracking of face-like stimuli and its subsequent decline. Cognition. 40(1-2):1-19

16. Butterworth G (1995) Origins of mind in perception and action. In: Moore C Dunham P (eds) Joint attention: its origins and role in development. Erlbaum, Hillsdale, NJ, pp 29-40

17. Bates E, Dick F (2002) Language, gesture, and the developing brain. Developmental Psychobiology. 40:293-310

18. Capone N, McGregor KK (2004) Gesture development: a review for clinical and research practices. Journal of Speech, Language, and Hearing Research. 47:173-186

19. Barnat S, Klein P, Meltzoff A (1996) Deferred imitation across changes in context and object: memory and generalization in 14-month-old infants. Infant Behavior and Development. 19:241-251

20. Tsao F, Liu H, Kuhl P (2004) Speech perception in infancy predicts language development in the second year of life: a longitudinal study. Child Development 75:1067-1084

21. Gao J, Duan YH, Lin S, Yang P, Song H, Jia QL et al (2017) Combined symptoms of social communication impairments: promising signs for early screening of autism. Biomedical Research. 28(11):4942-4945

22. Portage translation team: El-Sayed Abd El-Kader, Gaber Abd El-Hammed, Rosan Saleh, Saleh Hazeen, Salah Abd-ElMonem, Kamelia Abd El- Fatah and Mona Sanad (1995). Portage development checklist Arabic version (1st Version): Egypt: Egyptian Ministry of Education.

23. Abu Hasseba A (2011) Standardization, translation and modification of the preschool language scale. Unpublished Ph. D. Dissertation. Ain Shams University, Cairo

24. AERA APA, NCME (1999) The standards for educational and psychological testing. AERA Publications Sales, Washington

25. Anastasi A, Urbina S. Psychological testing (7th ed.). Upper Saddle River, NJ: Prentice Hall; 1997. p113.

26. Field A (2009) Discovering statistics using SPSS, 3rd edn. SAGE Publications Ltd, London

27. Määttä S. Developmental pathways of language development: a longitudinal predictive study from prelinguistic stage to outcome at school entry. Suutama T, (eds.). Jyväskylä: University Printing House: Jyväskylä; 2017.

28. Gad-Allah H, Abd-Elraouf S, Abou-Elsaad T, Abd-Elwahed M (2012) Identification of communication disorders among Egyptian Arabic-speaking nursery schools' children. Egyptian Society of Ear, Nose, Throat and Allied Sciences. 13(2):83-90

29. Bates E, Camaioni L, Volterra V (1975) The acquisition of performatives prior to speech. Merrill-Palmer Quarterly. 21:205-226

30. Adamson LB, Bakeman R, Deckner DF, Romski MA (2009) Joint engagement and the emergence of language in children with autism and Down syndrome. Journal of Autism and Developmental Disorders. 39:84-96

31. Brooks R, Meltzoff AN (2008) Infant gaze following and pointing predict accelerated vocabulary growth through two years of age: a longitudinal growth curve modeling study. Journal of Child Language. 35:207-220

32. Beuker KT, Rommelse NNJ, Donders R, Buitelaar JK (2013) Development of early communication skills in the first two years of life. Infant Behavior and Development. 36:71-83

33. Laakso ML, Poikkeus AM, Katajamäki J, Lyytinen P (1999) Early intentional communication as a predictor of language development in young toddlers. First Language. 19:207-231 
34. Colonnesi C, Stams GJJM, Koster I, Noom MJ (2010) The relation between pointing and language development: a meta-analysis. Developmental Review. 30:352-366

35. Heimann M, Strid K, Smith L, Tjus T, Ulvund SE, Meltzoff AN (2006) Exploring the relation between memory, gestural communication, and the emergence of language in infancy: a longitudinal study. Infant and Child Development. 15:233-249

36. Bruce B, Kornfält R, Radeborg K, Hansson K, Nettelbladt U (2003) Identifying children at risk for language impairment: screening of communication at 18 months. Acta Paediatrica. 92:1090-1095

37. McCathren RB, Yoder PJ, Warren SF (1999) The relationship between prelinguistic vocalization and later expressive vocabulary in young children with developmental delay. Journal of Speech, Language, and Hearing Research 42:915-924

38. Newman R, Ratner NB, Jusczyk AM, Jusczyk PW, Dow KA (2006) Infants' early ability to segment the conversational speech signal predicts later language development: a retrospective analysis. Developmental Psychology. 42:643-655

39. Smith L (1998) Predicting communicative competence at 2 and 3 years from pragmatic skills at 10 months. International Journal of Language \& Communication Disorders. 33:127-148

40. Lee J (2011) Size matters: early vocabulary as a predictor of language and literacy competence. Applied Psycholinguistics. 32:69-92

41. Marchman VA, Fernald A. Speed of word recognition and vocabulary knowledge in infancy predict cognitive and language outcomes in later childhood. Developmental Science. 2008;11: 9-16.

42. Kaiser AP, Roberts MY (2011) Advances in early communication and language intervention. Journal of Early Intervention. 33:298-309

43. Piaget J (1971) The construction of reality in the child. Ballantine Books, New York

44. Rescorla $L$ (2002) Language and reading outcomes to age 9 in late-talking toddlers. Journal of Speech, Language, and Hearing Research. 45:360-371

45. Rescorla $L$ (2005) Age 13 language and reading outcomes in late-talking toddlers. Journal of Speech, Language, and Hearing Research. 48:459-472

46. Rescorla L (2009) Age 17 language and reading outcomes in late-talking toddlers: Support for a dimensional perspective on language delay. Journal of Speech, Language, and Hearing Research 52:16-30

47. Rescorla L. Late-talking toddlers - a 15-year follow-up. Rescorla LA, Dale PS, (ed.). Late talkers: Language development, interventions, and outcomes. Baltimore, MD: Brookes; 2013. 219-239

48. Darrah J, Hodge M, Magill-Evans J, Kembhavi G (2003) Stability of serial assessments of motor and communication abilities in typically developing infants - implications for screening. Early Human Development. 72:97-110

49. Charman T, Baron-Cohen S, Swettenham J, Baird G, Drew A, Cox A (2003) Predicting language outcome in infants with autism and pervasive developmental disorder. Int J Lang Commun Disord. 38(3):265-228

50. Baron-Cohen S, Allen J, Gillberg C (1992) Can autism be detected at 18 months? The needle, the haystack, and the CHAT. British Journal of Psychiatry 161:839-843

51. Aydin A (2016) Development of the parent form of the preschool children's communication skills scale and comparison of the communication skills of children with normal development and with autism spectrum disorder. Educational sciences: theory and Practice. 16(6):2005-2028

52. Henderson LM, Yoder PJ, Yale ME, McDuffie A. Getting the point: electrophysiological correlates of protodeclarative pointing. International Journal of Developmental Neuroscience. 2002;20(3-5): 449-458 by

53. Wetherby A, Cain D, Yonclas D, Walker V (1988) Analysis of intentional communication of normal children from the prelinguistic to the multiword stage. Journal of Speech and Hearing Research. 31:240-252

54. Seibert J, Hogan A, Mundy P (1982) Assessing interactional competencies: the early social communication scales. Infant Mental Health Journal. 3:244-245

55. Mundy P, Gomes A (1998) Individual differences in joint attention skill development in the second year. Infant Behavior and Development. 21:469-482

56. Mundy P, Sigman M, Ungerer J, Sherman T (1987) Nonverbal communication and play correlates of language development in autistic children. Journal of Autism and Developmental Disorders 17:349-364

57. Ulvund S, Smith L (1996) The predictive validity of nonverbal communicative skills in infants with perinatal hazards. Infant Behavior and Development. 19:441-449

58. Kasari C, Paparella T, Freeman S, Jahromi L (2008) Language outcome in autism: randomized comparison of joint attention and play interventions. J Consult Clin Psychol. 76:125-137
59. Howlin P, Moore A (1997) Diagnosis of autism: a survey of over 1200 patients in the UK. Autism. 1:135-162

60. Siegel B, Pliner C, Eschler J, Elliott GR (1988) How children with autism are diagnosed: difficulties in identification of children with multiple developmental delays. J Dev Behav Pediatr. 9(4):199-204

61. Wu Z, Gros-Louis J (2014) Infants' prelinguistic communicative acts and maternal responses: relations to linguistic development. First Language. 34:72-90

62. Paavola L, Kunnari S, Moilanen I (2005) Maternal responsiveness and infant intentional communication: implications for the early communicative and linguistic development. Child: Care, Health and Development. 31:727-735

63. Goldin-Meadow S (2007) Pointing sets the stage for learning language--and creating language. Child Dev. 78(3):741-745

64. Iverson JM, Capirci O, Volterra V, Goldin-Meadow S (2008) Learning to talk in a gesture-rich world: early communication of Italian vs. American children. First Language. 28:164-181

65. Capirci O, Iverson JM, Pizzuto E, Volterra V (1996) Gestures and words during the transition to two-word speech. Journal of Child Language. 23:645-673

66. Fenson L, Dale PS, Reznick JS, Bates E, Thal DJ, Pethick SJ (1994) Variability in early communicative development. Monographs of the Society for Research in Child Development. 59:1-185

67. McLean J, Snyder-McLean L (1999) How children learn language. San Diego, CA, Singular

68. Bushnell IWR (2001) Mother's face recognition in newborn infants: learning and memory. Infant and Child Development. 10:67-74

69. Walden TA, Baxter A (1989) The effect of context and age on social referencing. Child Development. 60(6):1511-1518

70. Walden TA, Ogan TA (1988) The development of social referencing. Child Development. 59(5):1230-1240

71. Hertenstein MJ (2001) Campos JJ. Emotion regulation via maternal touch Article in Infancy 2(4):549-566

72. Hornik R, Risenhoover N, Gunnar M (1987) The effects of maternal positive, neutral, and negative affective communication on infant responses to new toys. Child Development. 58(4):937-944

73. Pepper J, Weitzman E (2004) It takes two to talk ${ }^{\bullet}$ : a practical guide for parents of children with language delays, 2nd edn. The Hanen Centre, Toronto

74. Law J, Boyle J, Harris F, Harkness A, Nye C (2000a) Prevalence and natural history of primary speech and language delay: findings from a systematic review of the literature. International Journal of Language \& Communication Disorders. 35:165-188

75. Reilly S, Wake M, Bavin EL, Prior M, Williams J, Bretherton L et al (2007) Predicting language at 2 years of age: a prospective community study. Pediatrics 120(6)

76. McLean M, Wolery M, Bailey DB (1996) Assessing infants and preschoolers with special needs, 3rd edn. Upper Saddle River, NJ, Pearson Education Inc

77. Dawson G, Webb S, Carver L, Panagiotides H, McPartland J (2004) Young children with autism show atypical brain responses to fearful versus neutral facial expressions of emotion. Dev Sci. 7(3):340-359

78. Dauch C, Imwalle M, Ocasio B, Metz AE (2018) The influence of the number of toys in the environment on toddlers' play. Infant Behavior and Development. 50:78-87

79. Zwaigenbaum L, Bryson S, Rogers T, Roberts W, Brian J, Szatmari P (2005) Behavioral manifestations of autism in the first year of life. Int J Dev Neurosci. 23(2-3):143-152

80. Tomasello M. Joint attention as social cognition. In C. Moore, P. J. Dunham, \& P. Dunham (Eds.). Joint attention: its origins and role in development. Hillsdale, NJ: Lawrence Erlbaum; 1995. p103-130.

81. Tomasello M (2000) The social-pragmatic theory of word learning. Pragmatics 10:401-413

82. Reilly S, Eadie P, Bavin EL, Wake M, Prior M, Williams J et al (2006) Growth of infant communication between 8 and 12 months: a population study. Journal of Paediatrics and Child Health. 42:764-770

83. Watt N, Wetherby A, Shumway S (2006) Prelinguistic predictors of language outcome at 3 years of age. Journal of Speech, Language, and Hearing Research. 49:1224-1237

84. Nip ISB, Green JR, Marx DB (2011) The co-emergence of cognition, language, and speech motor control in early development: a longitudinal correlation study. Journal of Communication Disorders. 44:149-160

85. Oller DK, Eilers RE, Neal AR, Schwartz HK (1999) Precursors to speech in infancy: the prediction of speech and language disorders. Journal of Communication Disorders. 32:223-245 
86. Määttä S, Laakso M, Tolvanen A, Ahonen T, Aroa T (2012) Developmental trajectories of early communication skills. Journal of Speech, Language, and Hearing Research. 55:1083-1096

87. Heilmann J, Weismer SE, Evans J, Hollar C (2005 Feb) Utility of the MacArthur-Bates communicative development inventory in identifying language abilities of late-talking and typically developing toddlers. Am J Speech Lang Pathol. 14(1):40-51

88. Bornstein MH, Hahn CS, Haynes O (2004) M. Specific and general language performance across early childhood: stability and gender considerations. First Language. 24:267-304

89. Dale PS, Price TS, Bishop DVM, Plomin R (2003) Outcomes of early language delay: I. Predicting persistent and transient language difficulties at 3 and 4 years. Journal of Speech, Language, and. Hearing Research. 46:544-560

\section{Publisher's Note}

Springer Nature remains neutral with regard to jurisdictional claims in published maps and institutional affiliations.

\section{Submit your manuscript to a SpringerOpen ${ }^{\circ}$ journal and benefit from:}

- Convenient online submission

- Rigorous peer review

- Open access: articles freely available online

High visibility within the field

- Retaining the copyright to your article 